\title{
Assessment of Age Effects on Ovarian Hemodynamics Using Doppler Ultrasound and Progesterone Concentrations in Cycling Spanish Purebred Mares
}

\author{
Francisco Requena ${ }^{1}$, María Joana A. P. M. Campos ${ }^{2}$, Andrés Luis Martínez Marín ${ }^{2}{ }^{\mathbb{D}}$, Rocío Camacho ${ }^{1}$, \\ Rosa M. Giráldez-Pérez ${ }^{1}$ (D) and Estrella I. Agüera ${ }^{1, *}$ \\ 1 Departamento de Biología Celular, Fisiología e Inmunología, Universidad de Córdoba, \\ Ctra. Madrid-Cádiz km 396, 14071 Córdoba, Spain; v02redof@uco.es (F.R.); m92caagr@uco.es (R.C.); \\ rgiraldez@uco.es (R.M.G.-P.) \\ 2 Departamento de Producción Animal, Universidad de Córdoba, Ctra. Madrid-Cádiz km 396, \\ 14071 Córdoba, Spain; z72macaj@uco.es (M.J.A.P.M.C.); pa1martm@uco.es (A.L.M.M.) \\ * Correspondence: ba1agbue@uco.es
}

\section{check for} updates

Citation: Requena, F.; Campos, M.J.A.P.M.; Martínez Marín, A.L.; Camacho, R.; Giráldez-Pérez, R.M.; Agüera, E.I. Assessment of Age Effects on Ovarian Hemodynamics Using Doppler Ultrasound and Progesterone Concentrations in Cycling Spanish Purebred Mares. Animals 2021, 11, 2339. https:// doi.org/10.3390/ani11082339

Academic Editor: Ramón Arias

Received: 30 June 2021

Accepted: 6 August 2021

Published: 8 August 2021

Publisher's Note: MDPI stays neutral with regard to jurisdictional claims in published maps and institutional affiliations.

Copyright: (c) 2021 by the authors. Licensee MDPI, Basel, Switzerland. This article is an open access article distributed under the terms and conditions of the Creative Commons Attribution (CC BY) license (https:// creativecommons.org/licenses/by/ $4.0 /)$.
Simple Summary: Power Doppler is a non-invasive imaging technique that allows complete monitoring of the ovary changes in cycling mares. We use Power Doppler to investigate differences in follicular diameter and corpus luteum area as well as in follicular and corpus luteum blood flows between young and mature Spanish Purebred mares. Young mares had higher follicular and corpus luteum blood flows as well as higher blood progesterone levels. Moreover, we found that blood progesterone levels could be predicted in both groups from corpus luteum blood flow with moderate precision and accuracy. These results support the usefulness of Power Doppler to monitor ovarian hemodynamics and the suitability of corpus luteum blood flow to estimate blood progesterone levels in cycling mares.

Abstract: In equine reproduction, accurate and timely detection of the moment of ovulation is of great importance. Power Doppler ultrasound technology is a non-invasive method that enables to assess the morpho-echogenic features and blood flow changes during the estral cycle in mares. The objective of the present study was to evaluate the influence of age on ultrasonographic parameters (follicular diameter, follicular blood flow-FBF, corpus luteum (CL) area and corpus luteum blood flow-CLBF) and blood plasma progesterone concentrations in cycling Spanish Purebred mares (15 less than 8 years old and 15 equal o higher than 8 years old). The ultrasound images obtained were analyzed with the Image Colour Summarizer software, which allows the quantification of the pixels of each image. Young mares had significantly higher FBF, CLBF and plasma progesterone levels. Moreover, linear regression analysis showed that blood progesterone levels could be predicted in both groups from CLBF with moderate precision and accuracy. In conclusion, Power Doppler was useful to assess ovarian hemodynamics. Our results support that age is a factor that significantly influences FBF and CLBF as well as blood progesterone concentration in mares. More studies would be needed to develop high precision and accuracy predictive models of blood progesterone concentration from CLBF measured by Power Doppler.

Keywords: Spanish purebred; power doppler; reproduction

\section{Introduction}

In equine reproduction, accurate and timely detection of the moment of ovulation is of great importance for the following reasons: (i) to ensure that ovulation occurred within the estimated time period after pre-ovulation; (ii) to establish the number of ovulations in relation to the number of pre-existing follicles, to be able to carry out the appropriate management in cases of twins, and (iii) to ensure the rupture and collapse of the follicle, 
followed by the release of the oocyte, thus allowing to detect possible cases of anovulatory follicles [1]. There is an increased permeability of blood vessels and an intense angiogenesis in the ovary during follicular development, ovulation, and subsequent corpus luteum (CL) formation.

Power Doppler ultrasound has the advantage of being a non-invasive method that enables to assess not only the morpho-echogenic features but also physiological events during the estral cycle such as the vascularization and blood flow (arterial and venous) of ovaries [2]. Measurement of follicle and CL blood flow (CLBF) can be achieved by this technique during the right-hander and also after the administration of hormonal treatments [3], which allows a deeper understanding of the reproductive pathophysiology of a mare. To make an in-depth study of the ovary, a useful tool to evaluate CL activity is to determine the blood concentration of progesterone [4]. Accordingly, any relationship between blood progesterone concentration and CLBF could be a predictive model to estimate the functionality of CL [5] avoiding stressful situations for animals [6] and providing a good prognosis and improving mare care and their practice management [7]. Power Doppler could contribute to the enhancement of equine reproductive management, achieving better use of genetic material and increasing financial return [8].

The Spanish Purebred is the most representative autochthonous equine breed in Spain. It has experienced a great boom in recent years and is widespread worldwide, so it is essential to guarantee its preservation by the Spanish State, as guarantor of a genetic heritage that cannot suffer any deterioration, avoiding possible risks of the dispersion of criteria that could compromise its adequate conservation [9]. A qualified breeding mare is three or more years old and meets the basic aptitude for reproduction, according to the established criteria referring to the breed prototype or morphology, functional test and examination of the reproductive system and veterinary control [9].

The objective of the present study was to evaluate the influence of age on ultrasonographic parameters (follicular diameter, follicular blood flow (FBF), CL area and CLBF) and blood plasma progesterone concentrations.

\section{Materials and Methods}

\subsection{Animals}

Cycling Spanish Purebred mares $(\mathrm{n}=30 ; 600-700 \mathrm{~kg}$ ), with a range of age between 4 and 19 years (average 9.3 years) were evaluated. The animals maintained a high body condition score (score $\geq 8$ ) during the experiment [10]. All mares had normal reproductive tract, typical oestrus cycles length and were free from infectious diseases. All mares were housed in stables with ab libitum access to water, hay and mineral salt. Mares were divided into two groups: young ( $<8$ years, $\mathrm{n}=15$ ) and old $(\geq 8$ years, $\mathrm{n}=15)$. The data collection was carried out in the "Miguel Ángel de Cárdenas" stud farm and located at San Pablo Farm (Écija, Seville, Spain). Animal care was fully in compliance with the University of Cordoba requirements on animal welfare and experimentation (2021PI/19).

\subsection{Mare Management}

All mares in this study underwent ovulation induction by administering a single IV injection of one dose of 3000 IU hCG (VETERIN CORION ${ }^{\circledR}$ ). In all of them, the appearance of ovulation was recorded between 24 - and 48-h post-administration by ultrasound. When the follicular diameter was $\geq 35 \mathrm{~mm}$, endometrial edema was verified by ultrasound and consistent cervical tone by rectal palpation [11].

Artificial insemination was carried out with refrigerated semen obtained from stallions from the herd itself. Pregnancy diagnosis was not included. In this study, it was decided to avoid sedation of the females to prevent the possible vasodilator effects of the sedative, although it minimizes artifacts in the color Doppler video recording. 


\subsection{Ultrasonography}

The ultrasound examinations (US) were performed by the first author, with a USB-mode and Doppler using the MyLabOneVet ultrasound (ESAOTE, Barcelona, Spain). The device was equipped with a 6-10 MHZ multifrequency linear transducer. All the US were performed by the same person to minimize the possible differences in the uptake and, consequently, the interpretation of the ultrasound images. The images were always captured with the same settings (10 MHz frequency, $70 \%$ mode B gain and $40 \%$ Power Doppler gain) and were recorded for later analysis on the same ultrasound machine. For Power Doppler imaging, a 30-s video was made of each structure from which 3 representative images were selected. Using the online version of Image Colour Summarizer ${ }^{\circledR}$ software, the chosen images were analyzed. This software allows the quantification of the percentage of colored pixels existing in an image, representative of ovarian blood flow. This technique transforms a qualitative analysis into a quantitative one. The user only has to introduce the file and process the selected image. Through the sum of all the colored pixels, the percentage of existing blood flow is obtained. The recorded Power Doppler images were taking in mares with preovulatory follicles $\geq 35 \mathrm{~mm}$ (Figure 1), which coincided with the administration of hCG (ovulation induction). The ovulation time was assumed between $36-40 \mathrm{~h}$ post-administration of hCG. The CL examination was $5.83 \pm 0.62$ and $6.40 \pm 0.54$ days in young and old age groups, respectively.

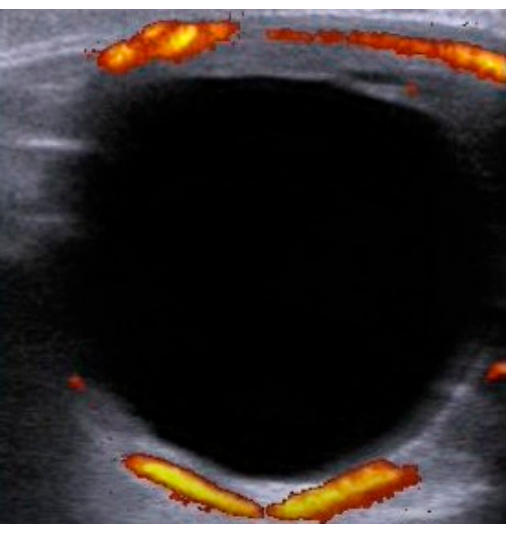

(a)

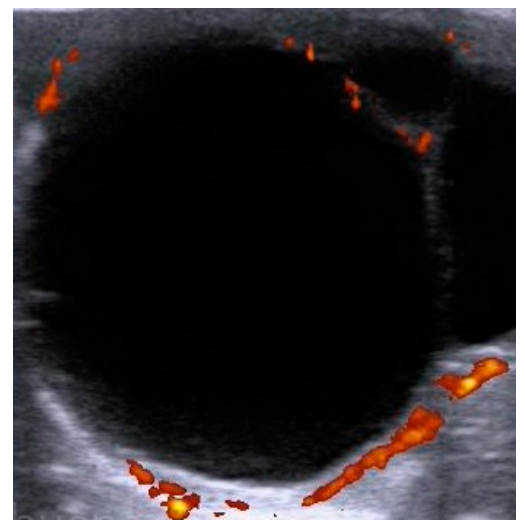

(b)

Figure 1. Representative image of preovulatory follicles, obtained at the time of ovulation induction, using Power Doppler ultrasound. (a) Blood flow follicle of a young mare; (b) Blood flow follicle of an aged mare.

Care was taken to do detailed examinations of the ovaries and uterus allowing a correct interpretation of the follicular dynamics. Along with the examination of both ovaries, images of the uterus were also recorded for a more complete analysis of the mare's reproductive dynamics.

In order to minimize possible errors and make the image of each ultrasound moment as representative as possible, the average of the parameters evaluated (diameter of the preovulatory follicle, percentage of FBF, area of the CL and percentage of CLBF) in the 6 images recorded from the total number of mares was evaluated. The mean value of the four ultrasound parameters studied was used for the statistical analysis.

\subsection{Progesterone Assay}

Jugular vein blood samples were obtained using heparinized $4 \mathrm{~mL}$ vacutainers, centrifugated $\left(1000 \times g\right.$ for $10 \mathrm{~min}$ at $\left.18-25^{\circ} \mathrm{C}\right)$ and plasma decanted and stored $\left(-20^{\circ} \mathrm{C}\right)$ until progesterone assay. Progesterone was evaluated with the commercial ELISA method EIA-5223 (DRG Instruments Gmbh, Marburg, Germany) which is specifically dedicated to equine [12]. 


\subsection{Statistical Analysis}

SAS University Edition 3.8 (SAS Institute, Cary, NC, USA) was used in the statistical analysis. The GLM procedure was used to investigate differences in ultrasound parameters and blood plasma progesterone concentrations due to age. Regression analysis in the GLMSELECT procedure was used to investigate the relationship between progesterone concentrations and CLBF. Model performance was assessed by the coefficient of determination (R2), the root of the mean square of prediction error (RMSPE), the RMSPE expressed as a proportion of the observed mean (\%RMSPE), and the concordance correlation coefficient (CCC). Furthermore, the mean square of prediction error (MSPE) was decomposed into mean bias (measure of precision), slope bias (measure of accuracy), and random error [9]. Statistical significance was declared at $p<0.05$.

\section{Results}

All of the 30 mares ovulated within the first $48 \mathrm{~h}(38.8 \pm 1.3 \mathrm{~h})$ after hCG treatment. The results from follicular and CL measurements and blood plasma progesterone concentrations are presented in Table 1. Blood plasma progesterone concentrations denoted that CL was functional.

Table 1. Mean \pm standard deviation (SD), minimum (Min) and maximum (Max) values of the follicle and corpus luteum ultrasonic parameters and blood plasma progesterone concentration from mares included in the study $(n=30)$.

\begin{tabular}{cccccccccc}
\hline \multicolumn{1}{c}{ Age Group } \\
\hline \multirow{2}{*}{ Parameters } & \multicolumn{3}{c}{ Old } & \multicolumn{3}{c}{ Young } & \multicolumn{3}{c}{ Total } \\
\cline { 2 - 11 } & Mean \pm SD & Min & Max & Mean \pm SD & Min & Max & Mean \pm SD & Min & Max \\
\hline Follicular diameter (mm) & $42.12 \pm 2.58$ & 38.40 & 46.30 & $43.67 \pm 2.94$ & 38.60 & 49.00 & $42.89 \pm 2.83$ & 38.40 & 49.00 \\
Follicular blood flow (\%) & $6.63 \pm 1.31$ & 4.20 & 8.53 & $8.00 \pm 1.59$ & 5.68 & 11.20 & $7.31 \pm 1.59$ & 4.20 & 11.20 \\
Corpus luteum area (mm) & $7.12 \pm 1.27$ & 4.38 & 8.63 & $7.79 \pm 1.23$ & 4.38 & 9.50 & $7.46 \pm 1.27$ & 4.38 & 9.50 \\
Corpus luteum blood flow (\%) & $16.78 \pm 3.29$ & 12.21 & 22.53 & $21.09 \pm 20$ & 16.65 & 23.85 & $18.94 \pm 3.46$ & 12.21 & 23.85 \\
Progesterone (ng/mL) & $5.04 \pm 0.65$ & 4.20 & 6.30 & $8.16 \pm 0.46$ & 7.36 & 8.90 & $6.60 \pm 1.68$ & 4.20 & 8.90 \\
\hline
\end{tabular}

Table 2 shows the comparison between both age groups. Young mares had significantly higher FBF $(p<0.05)$, CLBF $(p<0.001)$ and plasma progesterone levels $(p<0.001)$. The CL area and follicular diameter were non significant $(p>0.05)$.

Table 2. Least squares mean of ultrasonic parameters and progesterone concentrations.

\begin{tabular}{ccccc}
\hline \multicolumn{5}{c}{ Age Group } \\
\hline Parameters & Old & Young & SEM $^{\mathbf{1}}$ & $p$ \\
\hline Follicular diameter $(\mathrm{mm})$ & 42.12 & 43.67 & 0.51 & 0.13 \\
Follicular blood flow (\%) & 6.63 & 8.00 & 0.29 & $<0.05$ \\
Corpus luteum area (mm) & 7.12 & 7.79 & 0.23 & 0.15 \\
Corpus luteum blood flow $(\%)$ & 16.78 & 21.09 & 0.63 & $<0.001$ \\
Progesterone (ng/mL) & 5.04 & 8.15 & 0.30 & $<0.001$ \\
\hline
\end{tabular}

${ }^{1}$ Standard error of the mean.

The best regression models obtained in the present study for predicting progesterone concentrations from CLBF data shown in Table 1 are presented in Equation (1) (all data), (2) (young mares) and (3) (aged mares).

$$
\begin{gathered}
\mathrm{P}_{4}(\mathrm{ng} / \mathrm{mL})=-0.392( \pm 1.1418)+0.369( \pm 0.0593) \times \mathrm{CLBF} \\
\mathrm{R}^{2}=0.58 ; \mathrm{RMSPE}=1.01 \mathrm{ng} / \mathrm{mL} ; \% \mathrm{RMSPE}=16.2 \% ; \mathrm{CCC}=0.73 \\
p<0.001
\end{gathered}
$$




$$
\begin{gathered}
\mathrm{P}_{4}(\mathrm{ng} / \mathrm{mL})=4.878( \pm 0.9960)+0.1555( \pm 0.0470) \times \mathrm{CLBF} \\
\mathrm{R}^{2}=0.46 ; \mathrm{RMSPE}=0.33 \mathrm{ng} / \mathrm{mL} ; \% \mathrm{RMSPE}=4.0 \% ; \mathrm{CCC}=0.63 \\
p<0.01 \\
\mathrm{P}_{4}(\mathrm{ng} / \mathrm{mL})=2.966( \pm 0.7313)+124( \pm 0.0428) \times \mathrm{CLBF} \\
\mathrm{R}^{2}=0.39 ; \mathrm{RMSPE}=0.49 \mathrm{ng} / \mathrm{mL} ; \% \mathrm{RMSPE}=9.7 \% ; \mathrm{CCC}=0.56 \\
p<0.05
\end{gathered}
$$

Three models were significant and showed moderate precision, moderate to high accuracy, and moderate to weak reproducibility according to $\mathrm{R}^{2}$, RMSPE, \%RMSPE and CCC values. Furthermore, precision and accuracy were reinforced by the fact that none of the models showed mean or linear bias, with nearly $100 \%$ of MSE due to random error. The best equation in terms of precision and reproducibility was Equation (1), but it had less accuracy than the other two equations.

\section{Discussion}

It is common to find aged mares in herds for their genetic value and for their performance. Reproductive aging in mares is a physiological process that affects their fertility; thus, it must be understood how reproductive parameters change with age [13]. The association between Power Doppler and hormonal measurements throughout the mare's oestrus cycle could allow to evaluate the reproductive ability in mares [14,15]. Power Doppler is a non-invasive technique that permits the visualization of the internal organs. It has the advantage of being non-disruptive to functions, without the risk of exposure to $\mathrm{X}$-ray radiation, and it allows frequent use, not only in isolated reproductive organs, but also the monitoring of complete reproductive events and ovarian hemodynamics $[11,16,17]$.

In the current study, Power Doppler allowed us to find significant differences in the follicular and CL vascular perfusion between young and aged mares 5-7 days after ovulation in concordance with Campos [8]. Our results agree with Bollwein et al. [4], Ginther et al. [18] and Alonso et al. [19], who reported maximum vascularization between 6-days and 8-days post-ovulation. It is well known that luteal vascularization is important in the supply of the nutrients and substrates required for the optimal function and maturity of the CL [20].

No differences were detected regarding follicle diameter and CL area in agreement with previous studies [21,22]. Consistent with those authors, age is a critical factor that influences the quantity and quality of the equine preantral follicle.

The concentrations of progesterone obtained denoted that corpora lutea were functional in all mares. The blood plasma progesterone levels quantified in this study support that the young mares $\mathrm{CL}$, from the fifth day after ovulation, had the functional ability to preserve the pregnancy until the placenta assumes its function [17]. Although aged mares had lower progesterone concentrations than younger ones, the values were higher than the minimal plasmatic level $(4 \mathrm{ng} / \mathrm{mL})$. Therefore, a low reproductive performance would not be expected in the aged mares of the current study [23]. Again, the physiological cause of the significant differences in plasma progesterone concentration between aged and young mares would be related to changes in characteristics of reproductive cycles [24]. Aging in mares affects the development of the dominant follicle. Moreover, higher postovulatory plasma progesterone concentrations in young vs. aged mares have been previously reported $[25,26]$. Although we used hCG treatment for ovulation induction, we did not establish the correlation between that treatment and progesterone concentrations. A study performed by Alonso et al. [19] suggested that hCG treatment did not rise progesterone concentrations.

In the present study, CLBF was found to be a moderately good predictor of plasma progesterone levels. These results would support the interest in Power Doppler as a noninvasive technique to quantify plasma progesterone levels in cycling mares. Moreover, CLBF and progesterone levels in mares have been found to be positively correlated [4,27]. Using the data presented by Ishak et al. [27] in Equation 1, plasma progesterone levels 
would be underpredicted by $21 \%$ from CLBF, which suggests that this kind of prediction needs refinement.

Sales et al. [17] found that Doppler ultrasound correlates with the progesterone concentration and the embryo transfer day in Mangalarga Marchador mares, which indicates that Doppler ultrasound could be an important tool in the selection of appropriate embryo recipient mares in Spanish Purebred.

\section{Conclusions}

Our results support that age is a factor that significantly influences FBF and CLBF as well as the plasma progesterone concentration in mares. Power Doppler was useful to assess ovarian hemodynamics. Progesterone plasma levels could be predicted from CLBF measured by power Doppler. More studies are needed to enhance the precision and accuracy of such predictions.

Author Contributions: Conceptualization, F.R. and E.I.A. methodology, F.R. and M.J.A.P.M.C.; software M.J.A.P.M.C.; formal analysis, A.L.M.M.; investigation, M.J.A.P.M.C., F.R. and R.C.; resources, M.J.A.P.M.C. and R.C.; data curation, A.L.M.M. and E.I.A.; writing — original draft preparation, E.I.A. and F.R.; writing - review and editing, E.I.A., F.R., R.C., A.L.M.M., M.J.A.P.M.C. and R.M.G.-P.; supervision, E.I.A. and F.R. All authors have read and agreed to the published version of the manuscript.

Funding: This research received no external funding.

Institutional Review Board Statement: The study was approved by the Ethics Committee of Universidad de Córdoba, Spain (protocol code 2021PI/19).

Informed Consent Statement: Not applicable.

Data Availability Statement: The data presented in this study are available in the article.

Acknowledgments: Miguel Ángel de Cardenas stud farm is gratefully acknowledged for providing the mares and allowing their staff to collaborate in this study.

Conflicts of Interest: The authors declare no conflict of interest.

\section{References}

1. Cuervo-Arango, J.; Newcombe, J.R. Ultrasound confirmation of ovulation in mares: A normal corpus luteum or a haemorrhagic anovulatory follicle? Reprod. Domest. Anim. 2013, 48, 105-111. [CrossRef]

2. Järvelä, I.Y.; Sladkevicius, P.; Kelly, S.; Ojha, K.; Nargund, G.; Campbell, S. Three-dimensional sonographic and power Doppler characterization of ovaries in late follicular phase. Ultrasound Obstet. Gynecol. 2002, 20, 281-285. [CrossRef] [PubMed]

3. Castro, T.; Oliveira, F.A.; Siddiquim, M.A.; Baldrighi, J.M.; Wolf, C.A.; Ginther, O.J. Stimulation of LH, FSH and luteal blood flow by GnRH during the luteal phase in mares. Theriogenology 2016, 85, 740-746. [CrossRef]

4. Bollwein, H.; Mayer, R.; Weber, F.; Stolla, R. Luteal blood flow during the estrous cycle in mares. Theriogenology 2002, 57, $2043-2051$. [CrossRef]

5. Vecchio, D.; Neglia, G.; Gasparrini, B.; Russo, M.; Pacelli, C.; Prandi, A.; D’Occhio, M.J.; Campanile, G. Corpus luteum development and function and relationship to pregnancy during the breeding season in the Mediterranean buffalo. Theriogenology 2012, 77, 1811-1815. [CrossRef] [PubMed]

6. Esposito, L.; Salzano, A.; Russo, M.; de Nicola, D.; Prandi, A.; Gasparrini, B.; Campanile, G.; Neglia, G. Corpus Luteum Color Doppler Ultrasound and Pregnancy Outcome in Buffalo during the Transitional Period. Animals 2020, 13, 1181. [CrossRef]

7. Robinson, N.E.; Sprayberry, K.A. Current Therapy in Equine Medicine; Elsevier: Amsterdam, The Netherlands, 2009.

8. Campos, M.J.A.P.M. Utilização de Doppler na Avaliação Hemodinâmica Ovárica de Éguas Pura Raça Espanhola: Estudo Piloto. Ph.D. Thesis, Universidade de Lisboa, Lisboa, Portugal, 2017.

9. Orden APA/3319/2002, de 23 de Diciembre por la que se Establecen las Normas Zootécnicas del Caballo Pura Raza Español; BOE-A-200225418; Boletín Oficial del Estado: Madrid, Spain, 2002.

10. Henneke, D.R.; Potter, G.D.; Kreider, J.L.; Yeates, B.F. Relationship between condition score, physical measurements, and body fat percentage in mares. Equine Vet. J. 1983, 15, 371-372. [CrossRef]

11. Brogan, P.T.; Henning, H.; Stout, T.A.E.; Ruijter-Villani, M. Relationship between colour flow Doppler sonographic assessment of corpus luteum activity and progesterone concentrations in mares after embyo tranfer. Anim. Reprod. Sci. 2016, 166, $22-27$. [CrossRef] 
12. Dufour, P.; Courtois, J.; Seynaeve, Y.; Peeters, S.; Le Goff, C.; Cavalier, E.; Ponthier, J. Development and validation of a liquid chromatography coupled to mass spectrometer (LC-MS) method for the simultaneous quantification of estrone-3-sulfate, progesterone, estrone and estradiol in serum of mares and American bisons. Res. Vet. Sci. 2021, 136, 343-350. [CrossRef] [PubMed]

13. Claes, A.; Ball, B.A.; Scoggin, K.E.; Roser, J.F.; Woodward, E.M.; Davolli, G.M.; Squires, E.L.; Troedsson, M.H.T. The influence of age, antral follicle count and diestrous ovulations on estrous cycle characteristics of mares. Theriogenology 2017, 15, 34-40. [CrossRef] [PubMed]

14. Ginther, O.J.; Gastal, E.L.; Gastal, M.O.; Beg, M.A. Effect of prostaglandine F2 alfa on ovarian, adrenal, and pituitary hormones and on luteal blood flow in mares. Domest. Anim. Endocrinol. 2007, 32, 315-328. [CrossRef] [PubMed]

15. Ferreira, J.C.; Ignacio, F.S.; Meira, C.D. Doppler ultrasonography principles and methods of evaluation of the reproductive tract in mares. Acta Sci. Vet. 2001, 39, 105-111.

16. Echevarria, L. La ecografía como técnica. Rev. Investig. Vet. Perú 2001, 12, 2.

17. Sales, F.A.B.M.; Azevedo, M.V.; Souza, N.M.; Ferreira-Silva, J.C.; Chaves, M.S.; Junior, V.R.; Rocha, J.M.; Dos Santos Filho, J.P.; Freitas, V.J.F.; Oliveira, M.A.L. Correlations of corpus luteum blood flow with fertility and progesterone in embryo recipient mares. Trop Anim. Health Prod. 2021, 22, 280. [CrossRef]

18. Ginther, O.J.; Gastal, E.L.; Gastal, M.O.; Utt, M.D.; Beg, M.A. Luteal blood flow and progesterone production in mares. Anim. Reproduc. Sci. 2007, 99, 213-220. [CrossRef] [PubMed]

19. Alonso, M.A.; Silva, L.A.; Affonso, F.J.; Lemes, K.M.; Celeghini, E.C.C.; Lan $\sqrt{ }$ Boni, R.; Carvalho, H.F.; de Arruda, R.P. Effect of hCG application at different moments of the estrous cycle on corpus luteum and uterine vascularization and serum progesterone concentration in mares. Anim. Reprod. 2019, 24, 317-327. [CrossRef] [PubMed]

20. Ginther, O.J. Reproductive Biology of the Mare. Basic and Applied Aspects, 2nd ed.; Equineservice Publishing: Cross Plains, WI, USA, 1992.

21. Alves, K.A.; Alves, B.G.; Gastal, G.D.A.; Haag, K.T.; Gastal, M.O.; Figueiredo, J.R.; Gambarini, M.L.; Gastal, E.L. Preantral follicle density in ovarian biopsy fragments and effects of mare age. Reprod. Fertil. Dev. 2017, 29, 867-875. [CrossRef]

22. Gastal, E.I.; Aguiar, F.L.N.; Gastal, G.D.A.; Alves, K.A.; Alves, B.G.; Figueiredo, J.R. Harvesting, processing, and evaluation of in vitro-manipulated equine preantral follicles: A review. Therigenology 2020, 156, 283-295. [CrossRef]

23. Marinone, A.I.; Mucci, N.; Kaiser, G.; Losinno, L.; Armendano, J.; Rodriguez, E.; Mutto, A.; Redolatti, C.; Cantatore, S.; Herrera, M.F.; et al. Reproductive Characteristics in old and young subfertile mares: Are they really different? J. Equine Vet. Sci. 2017, 55, 90-96. [CrossRef]

24. Carnevale, E.M. The mare model for follicular maturation and reproductive aging in the woman. Theriogenology 2008, 61, 23-30. [CrossRef]

25. Vanderwall, D.K.; Woods, G.L.; Freeman, D.A.; Weber, J.A.; Rock, R.W.; Tester, D. F (1993). Ovarian follicles, ovulations and progesterone concentrations in aged versus young mares. Theriogenology 1993, 40, 21-32. [CrossRef]

26. Fonda, E.S.; Hackett, G.E.; Burrill, M.J.; Cogger, E.A. A comparison of LH and progesterone secretion in young and aged mares. J. Anim. Sci. 1988, 1, 429.

27. Ishak, G.M.; Bashir, S.T.; Gastal, M.O.; Gastal, E.L. Pre-ovulatory follicle affects corpus luteum diameter, blood flow, and progesterone production in mares. Anim. Reprod. Sci. 2017, 187, 1-12. [CrossRef] [PubMed] 